\title{
Configuración y contextualización de las galerías fotográficas en los diarios online. Propuesta de analítica aplicada
}

\author{
Por Joaquín López-Del-Ramo
}

Resumen: Análisis de las galerías fotográficas en los diarios digitales españoles El mundo, La vanguardia, Sur y La voz de Galicia, realizado en enero de 2010. Se emplea una pauta de análisis original con indicadores para examinar los tipos, configuración y valor informativo de las galerías. Se verifica su importancia cuantitativa, creciente especialización, diseño, acceso y funciones. Se concluye que las galerías son abundantes, tienen buena visibilidad y presentan gran variedad temática. La falta de vínculos con etiquetado estándar, los accesos redundantes y la escasa ampliación de tamaño son carencias destacadas. Es necesaria una mayor contextualización informativa de las fotos, reforzando la trama hipertextual entre las galerías y las páginas de las informaciones a las que aluden.

Palabras clave: Fotoperiodismo, Ciberperiodismo, Fotografía, Diseño periodístico, Fotogalerías, El mundo, La vanguardia, Sur, La voz de Galicia.

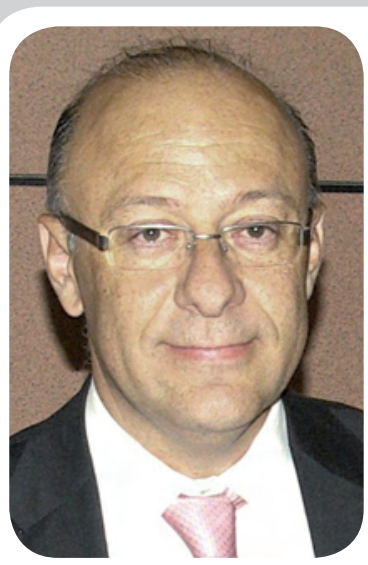

Joaquín López-Del-Ramo es doctor en periodismo por la Univ. Complutense de Madrid, experto en información socio-económica por el mismo centro y master de IBM. Ejerce como profesor de diseño de la información periodística y tecnologías multimedia en la Univ. Rey Juan Carlos de Madrid, donde fue responsable de la coordinación académica de las licenciaturas de periodismo y publicidad-RRPP en la modalidad online. Ha participado como miembro e investigador principal en proyectos de investigación sobre diseño gráfico y editorial, fotografía, usabilidad y diseño web, así como en otros de innovación educativa relacionados con el e-learning. Es miembro del GEAC (Grupo de Estudios Avanzados de la Comunicación) y fundador del CODI (Grupo de estudios de la Comunicación y Diseño de la Información), ambos de la Univ. Rey Juan Carlos. Sus líneas de investigación son el fotoperiodismo, diseño y usabilidad en la web y diseño periodístico.

\section{Title: Configuration and contextualization of the photo galleries in on-line newspapers. Applied analytical proposal}

Abstract: The photo galleries in four Spanish digital journals --El mundo, La vanguardia, Sur and La voz de Galiciawere analysed in January 2010. A model was designed with indicators to examine the topics, configuration and informative value of the galleries. The study included the quantitative importance of the galleries, their increasing specialization and heterogeneous design, access and functionality. The conclusions are: the galleries are abundant, have good visibility and present a great variety of themes. The lack of standardized labeling of links, redundant access and little magnification of the images are significant drawbacks. There should be more informative contextualization of the photos, enhancing the hypertext linkage between the galleries and information pages to which they refer.

Keywords: Photojournalism, Cyberjournalism, Photography, Journalistic design, Photogalleries, El mundo, La vanguardia, Sur, La voz de Galicia.

López-Del-Ramo, Joaquín. “Configuración y contextualización de las galerías fotográficas en los diarios on-line. Propuesta de analítica aplicada”. El profesional de la información, 2010, septiembre-octubre, v. 19, n. 5, pp. 469-475.

DOI: $10.3145 /$ epi.2010.sep.04

\section{Introducción}

En la evolución de los periódicos en internet se distinguen varias etapas desde su nacimiento, que en España tuvo lugar a mediados de la década de los 90 del siglo pasado. Partiendo de la inicial similitud en contenido y periodicidad con las ediciones impresas, los diarios online fueron estableciendo de forma gradual factores distintivos, que han sido claramente identificados por Juan-Carlos Marcos-Recio (2005, p. 68): primero fue una frecuencia de actualización con lapsos temporales gradualmente menores, y en una fase pos- terior se actuó en el diseño, mejorando la presentación de la información e incorporando otros servicios con el fin de hacer un producto de calidad y con un estilo y aspectos de contenido claramente diferenciados respecto de los diarios de papel.

Como consecuencia de este proceso, durante este tiempo los periódicos digitales han alterado de forma muy notable las rutinas de tratamiento y uso de los diferentes componentes de la noticia. Si ello es apreciable en el aspecto redaccional, quizás se hace aún más evidente en lo que atañe al diseño, tanto de 
la composición estructural de la página, como de los elementos textuales y gráficos de superficie. De entre ellos, la fotografía es la que ha experimentado mayores mutaciones en comparación con la prensa de papel, que en lo sustancial se han traducido en una merma de su importancia informativa, en el sentido clásico del fotoperiodismo.

\section{"Se ha constatado el empleo masivo de la fotografía en los periódicos digitales, pero con una función meramente decorativa"}

Los pocos trabajos previos realizados sobre esta materia constatan el empleo masivo de la fotografía en los periódicos digitales, pero también el hecho de que ésta suele desempeñar una función meramente decorativa o de relleno, aportando poco o nulo valor añadido a la comprensión e interpretación de las noticias. En paralelo y en contraste positivo con lo anterior, hay que destacar la aparición de nuevas fórmulas fotoperiodísticas que abren amplias posibilidades de enriquecimiento visual e informativo. Entre ellas destacan las galerías fotográficas, que posibilitan la publicación de fotos de mayor tamaño y calidad, así como su agrupación por temas y otras potencialidades añadidas, no del todo exploradas.

Para López-Aguirre (2009, p. 106) la galería fotográfica es un "producto ciberperiodístico que muestra un suceso noticioso mediante un conjunto de imágenes ordenadas secuencialmente. Cuenta con el apoyo de un título y regularmente pies de foto". No obstante, podemos constatar que no siempre las galerías están ligadas a un hecho informativo concreto, sino que casi todos los diarios disponen de galerías genéricas y heterogéneas, tipo "cajón de sastre". Hay también galerías que dan cabida a fotos de la ciudad o provincia a la que pertenece el periódico, galerías dedicadas a eventos como fiestas, fin de semana, etc. El tipo más novedoso lo integran las galerías de los lectores, cuyo crecimiento sigue en auge, como certifica el trabajo de Johnson para The Bivings Group (2008) sobre el uso de internet en los principales diarios de EUA, que cifra en el $58 \%$ los periódicos que soportan la inclusión de fotos de los lectores, frente al 18\% que admite vídeos y el $15 \%$ artículos. Además de los tipos mencionados, YusteRobles, Sandoval-Martín y Franco-Álvarez (2006) distinguen entre galerías sobre un hecho noticioso concreto y de temáticas especiales, dedicadas en exclusiva a acontecimientos impactantes, tales como catástrofes o conmemoraciones importantes.
Uno de los inconvenientes más atribuidos a las galerías es la falta de contexto o asociación referencial entre las imágenes y las informaciones a las que aluden, sumado a la publicación de imágenes genéricas o sin relación con ninguna noticia. En ello coinciden los trabajos de Sánchez-Vigil, Marcos-Recio y Villegas-Rovar (2007, p. 213), Armentia-Vizuete (2005, p. 20) y Caminos, Marín-Murillo y Armentia-Vizuete (2006, p. 33). Este "desenganche" entre el cuerpo informativo textual y la foto da pie a contemplar las galerías como un elemento donde la imagen cobra autonomía y por tanto mayor realce, pero, como contrapartida negativa, debe tenerse en cuenta que pocas fotografías aportan por sí mismas las claves para la comprensión íntegra de un hecho noticioso, incluso con el apoyo de un título y un pie textual.

\section{"Un inconveniente es la falta de asociación entre las imágenes y las informaciones a las que aluden"}

Un aspecto sustancial es la pertenencia de las galerías al entramado hipertextual del propio periódico, así como la existencia de un entorno de vinculación a nivel interno entre las fotos que la componen. Por ello, en palabras de Isabel Villa (2008, p. 310) "las galerías hacen posible concebir una nueva estructura, propia del hipertexto, que trasciende el valor unitario de las tomas para construir redes, de tal forma que la mayoría de sus nodos posibilitan infinitas conexiones". Precisamente, la vinculación entre las fotos de las galerías y las informaciones a las que se refieren es la fórmula que puede permitir la articulación narrativa entre las imágenes y su contexto informativo, supliendo así la posible descontextualización.

El trabajo de Sánchez-Vigíl, Marcos-Recio y Villegas-Tovar (2007, p. 218) constata otro aspecto revelador: el tratamiento de las imágenes de las galerías presenta particularidades propias con respecto al de las fotos de portada o de informaciones interiores, lo cual también puede singularizarlas como un género novedoso. Se trata de una idea aún embrionaria, puesto que hasta ahora los trabajos que han tocado este asunto, como el ya citado de Caminos, Marín-Murillo y Armentia-Vizuete (2006, p. 33), se limitan a identificar la fórmula "galería" con el tradicional reportaje fotográfico de la prensa escrita, sin ir más allá.

A la luz de lo expuesto, se establecen las siguientes hipótesis de trabajo: 
- Las galerías fotográficas se han convertido en un elemento cada vez más utilizado en los diarios digitales, y tienden a la especialización temática.

- No hay pautas estándar en cuanto a su diseño, modo de entrada y configuración, aunque en general su funcionamiento es simple.

- Las fotos se encuentran fuera de su contexto informativo, al visualizarse de forma autónoma e inconexa con respecto al cuerpo de las noticias.

En función de todo ello, los principales objetivos de este trabajo son:

a) Realizar una caracterización de las galerías fotográficas en los diarios online, tanto cuantitativa como cualitativa.

b) Proponer una pauta de análisis básica de las galerías fotográficas de los periódicos digitales que integre variables hasta ahora dispersas e incorpore otras nuevas, adecuadas al objetivo expuesto con anterioridad.

c) Utilizar dicha pauta para obtener datos que permitan confrontar las tendencias registradas en anteriores trabajos o aportar otras nuevas.

\section{"Las galerías poseen una gran visibilidad en las páginas principales de los diarios digitales"}

\section{Método}

Se procedió al diseño y elaboración de una ficha de análisis compuesta por 19 indicadores sobre las propiedades básicas de las galerías agrupadas por categorías (tabla 1).

Se escogieron los 4 diarios digitales El mundo, La vanguardia, Sur de Málaga y La voz de Galicia, con la intención de alcanzar un grado de representatividad y coherencia adecuado. Se trata de periódicos pertenecientes a grupos editoriales diferentes y editados en distintos puntos de España, ya que se pretendía cubrir un target tanto nacional como regional/local. La elección de estas cabeceras se justifica, asimismo, porque son líderes de audiencia en sus respectivos segmentos. Según los datos de la OJD-interactiva correspondientes a los primeros meses de 2010 , los dos periódicos digitales generalistas a nivel nacional con mayor número de usuarios únicos son El mundo (pionero en la inclusión de galerías fotográficas) y La vanguardia, mientras que La voz de Galicia y Sur (éste auditado por Nielsen Online en el mismo período) figuran entre las tres primeras posiciones en el ranking de los diarios regionales.

Las consultas se realizaron en las mismas franjas horarias para todos los periódicos, correspondientes a las ediciones de tarde, y en días laborables, en concreto los siguientes: del martes 19 al viernes 22 de enero y el lunes 25 de enero de 2010. En el análisis únicamente se consideraron las galerías accesibles desde la portada de los diarios, en cualquiera de los modos de acceso disponibles, y desde las páginas interiores de las noticias destacadas en esa misma portada.

\section{Resultados}

En aras a la concreción y economía de espacio, se presentan los cómputos globales de cada medio sin desglosar por días.

\section{Acceso y tipos (indicadores 1 a 5)}

En la totalidad de las páginas principales de los periódicos analizados se da una presencia evidente de galerías. El número de galerías visualizables desde portada en el conjunto de la muestra es de 54 , que sobre un total de 20 portadas analizadas da una media de 2,7 galerías por portada.

Respecto al modo de acceso a las mismas, se registran los siguientes:

- Visualización directa en portada: fórmula usada en todos los periódicos y que posee dos variantes: a) la galería ocupa un espacio autónomo propio, del mismo modo que lo hacen las noticias o llamadas; b) la galería ilustra la entradilla a una noticia, como la fotografía tradicional, lo cual es un uso novedoso y observable en todos los diarios analizados.

- Mediante llamada a una galería o grupo de galerías, pero sin ejecución directa. Esta fórmula se emplea normalmente para entrar en galerías de secciones o de temas especiales, y también se da en todos los casos analizados.

- Por medio de link en botoneras de navegación principal, casi siempre utilizado para acceder a la galería general tipo "Imágenes del día", desde la que en algunos diarios se puede tener acceso a su vez a otras organizadas por temas. Este link en la botonera principal se encuentra en todos los periódicos.

- Por medio de hipervínculo presente en la llamada a una noticia, en cuyo caso se entra a una galería de fotos específica de la noticia en cuestión. Es el modo menos utilizado.

El total de accesos a galerías desde la página principal de estos modos en el conjunto de la muestra es de 120 , lo que da una media de 6 por cada edición del diario, aparte de las 2,7 de visualización directa 


\section{Acceso y tipos}

¿Presencia evidente de galerías en la portada?

1 Constatar si en la página principal se visualizan galerías, bien de ejecución directa, o en llamadas, a modo de las noticias destacadas.

2 ¿Galerías de visualización directa en portada?

2 Cuantificar el número de galerías que pueden visualizarse en portada sin acceder a interiores.

3 Otros modos de acceso

3 Indicar si hay otras formas de acceso a las galerías desde portada y cuáles son.

Etiqueta/s para acceder

4 Rótulos empleados en menús y barras de navegación para vincular a las galerías. Comprobar si hay uniformidad entre los mismos.

Tipos

$5 \quad$ Grado de variedad y especialización de las galerías. Se consideran los siguientes tipos: 1) genéricas, 2) de secciones informativas, 3) de noticias específicas, 4) de acontecimientos o temas especiales, 5) de lectores o participativas.

\section{Aspecto-configuración}

$6 \quad$ ¿Tienen todas el mismo diseño o estilo?

$6 \quad$ Establecer si existe unidad visual y estilística entre las galerías de un mismo diario.

7 Indicadores visuales de foto

Tipos de elementos iconográficos utilizados para esta función y cuáles son.

8 Buena nitidez de las miniaturas

8 Confirmar si el tamaño de las miniaturas es suficiente como para distinguir las fotos en sus detalles básicos.

9 ¿Mezcla fotos con vídeos?

9 Registrar el empleo de esta práctica de mezcla de formatos, que puede producir confusión en el lector.

10 ¿Mezcla fotos con otros gráficos?

10 Registrar el empleo de esta práctica de mezcla de formatos, que puede producir confusión en el lector.

\section{Funcionalidad}

11 ¿Tienen todas el mismo funcionamiento?

Si todas las galerías de un mismo periódico tienen un funcionamiento interno semejante.

¿Están automatizadas en una presentación?

12 Si en alguna galería se utiliza este recurso, por el que las fotos se visualizan de forma dinámica sin previa actuación del lector.

13 ¿Tiene el lector control sobre la presentación?

Si el lector puede lanzar, pausar o detener la presentación.

14 ¿Permite ampliar las fotos?

Si las fotos permiten su ampliación en un tamaño superior al marco de la propia galería.

\section{Contextualización informativa}

15 ¿Tienen las fotos pie o texto explicativo?

Verificar este uso. La inclusión de títulos, pies de foto o párrafos anexos es un elemento de contextualización básico.

¿Permite el pie relacionar bien las fotos con la noticia?

16 Comprobar si el mensaje contenido en estos apoyos textuales hace posible encuadrar la imagen claramente en una determinada noticia.

17 ¿Hay noticias interiores ilustradas con galería propia?

17 Conocer si se usa este recurso por lo novedoso del mismo y porque supone un enriquecimiento de la ilustración fotográfica de la noticia.

¿Las mismas fotos se usan en galerías y en noticias?

18 Corroborar si el diario hace un empleo versátil de las fotografías y si éstas sirven como nexo visual de diferentes espacios, secciones o noticias.

19 ¿Hay hipervínculos desde galerías a noticias?

Constatar esta práctica, que optimiza la contextualización de la imagen dentro del hecho informativo al que refiere.

Tabla 1. Indicadores que examinan las propiedades básicas de las galerías

en portada. Así, la media total de accesos a galerías por portada es de 8,7 , pero con la matización de que algunos son redundantes, pues conducen a una misma galería.

Se verifica que no se dispone de etiquetado estándar para los vínculos o botoneras de entrada a las galerías desde la página principal sino que, por el contrario, estos textos son muy variados, y en muchas ocasiones redundantes o confusos: "Fotos", “Álbum”, “Álbum de la semana", "Galería de fotos", "Multimedia", etc.

Tomando la muestra en su conjunto, se constata la presencia de los cuatro tipos de galerías considerados: genéricas, de noticia, de sección, de acontecimiento y de lectores, algunas de las cuales generan subtipos, como por ejemplo las específicas de cada sección del diario, lo que apunta a una apreciable diversificación. 


\section{Aspecto y configuración (indicadores 6 a 10)}

En la mayoría de los casos analizados las galerías de un mismo periódico no tienen idéntico diseño y estilo. Lo más frecuente es que cada uno de los tipos de galerías consignados en el epígrafe anterior posea un diseño propio, con ligeras variantes, y en algunos casos (especialmente las dedicadas a un acontecimiento específico) resulta ser personalizado.

Entrando en detalles de configuración, se comprueba que dentro de las galerías el empleo de miniaturas no es en ningún caso el único modo de representación de las imágenes, ni siquiera el más usado, sino que son más utilizados pequeños iconos a modo de botón y secuencias de números. Con ellos se pretende indicar al lector de una forma más o menos clara y metafórica, el número de imágenes de que consta la galería. En otros casos sólo se visualiza un cursor secuencial sin pistas visuales para indicar el total de fotos, pero se trata de un uso minoritario.

\section{"La falta de estandarización del etiquetado y la multiplicidad de modos de entrada genera cierta confusión en el lector"}

En las galerías que emplean miniaturas el número de las mismas es bastante reducido, oscilando entre un mínimo de 2 y un máximo de 8 fotogramas, sin que nunca aparezcan simultáneamente miniaturas de todas las fotos. En todos los casos tienen un tamaño suficiente como para ser distinguidas con claridad por el lector. Asimismo, hay unanimidad en no mezclar dentro de la galería fotos con otros elementos visuales, como vídeos o gráficos, práctica que sí se ha constatado en otros lugares.

\section{Funcionalidad (indicadores 11 a 14)}

La simplicidad en el funcionamiento es uno de los valores de las galerías, si bien se aprecia que éste, siendo parecido, nunca es idéntico en todas las de un mismo diario. La tendencia mayoritaria es que las fotos puedan visualizarse en modo presentación, pero dejando el control de ejecución a voluntad del lector. Sólo en La voz de Galicia encontramos galerías en las que la presentación arranca de forma automática, pero aun asî el usuario tiene control sobre ella, por lo que las diferencias funcionales son mínimas en este sentido.

En caso de contar con miniaturas, números o iconos indicativos de foto, es posible la navegación aleatoria, pero en aquellas galerías que únicamente presentan un cursor "adelante-atrás" se obliga a una navegación secuencial, además de que el lector desconoce la extensión de la galería, al carecer de testigos visuales del número de fotos que la integran. Esta última solución es la menos empleada por su escasa o nula usabilidad. En cuanto a la posibilidad de visualizar las fotos de la galería en modo ampliado, en contra de lo que podía preverse, sólo se da en uno de los periódicos analizados, El mundo, pero las fotos están pixeladas.

\section{Contextualización informativa (indicadores 15 a 19)}

La mayoría de las fotografías presentes en las galerías llevan pies de foto explicativos y títulos que hacen posible relacionar la foto con el hecho noticioso (cierto que a veces éste tiene insuficiente valor informativo) al que remite.

En 3 de los periódicos analizados se produce la inserción de galerías en páginas interiores de noticias, en ocasiones combinadas con otras fotografías y a veces como ilustración única. Esta es otra práctica relativamente novedosa que de forma gradual parece imponerse en los ciberdiarios y suele ir unida a la utilización de las mismas fotos simultáneamente como ilustración de una información y como parte de otras galerías.

Uno de los procedimientos utilizados para contextualizar las imágenes de las galerías con los hechos informativos a los que se refieren es la interconexión mediante hipervínculos entre dichas fotos y las páginas de las noticias correspondientes. El modo más claro de hacerlo es mediante un texto (del tipo "ir a la noticia") situado fuera de la foto, en un margen o dentro del pie o texto de acompañamiento que suele llevar. Esta práctica se produce en todos los periódicos examinados, pero se aplica desigualmente en las galerías.

\section{Conclusiones}

a) Las galerías poseen una gran visibilidad en las páginas principales de los diarios digitales. Su presencia directa, número de formas de acceso y especialización temática ponen de manifiesto su creciente importancia cuantitativa y cualitativa.

b) Más que las diferencias de diseño y de funcionamiento, la falta de estandarización del etiquetado y la multiplicidad de modos de entrada pueden generar cierta confusión en el lector. Esto ocurre, por ejemplo, cuando se llega a la misma galería desde vínculos con etiquetas diferentes y a veces redundantes; o, en sentido inverso, cuando desde etiquetas parecidas se acaba llegando a galerías distintas por contenido o ubicación. La navegación interna es sencilla y no presenta limitaciones, salvo en aquellas que carecen de miniaturas o iconos representativos de las fotos y/o sólo proporcionan cursores de navegación secuencial.

c) Las galerías se prefiguran como secciones independientes en los periódicos online, con una naturaleza 


\begin{tabular}{|c|c|c|c|c|c|}
\hline Periódico & $\begin{array}{c}\text { 1. Presencia } \\
\text { evidente de galerías }\end{array}$ & $\begin{array}{c}\text { 2. Galerías de } \\
\text { visualización directa }\end{array}$ & $\begin{array}{c}\text { 3. Otros modos } \\
\text { de acceso (*) }\end{array}$ & $\begin{array}{c}\text { 4. Etiquetas } \\
\text { diferentes }\end{array}$ & $\begin{array}{c}\text { 5. Tipos de } \\
\text { galerías (**) }\end{array}$ \\
\hline El mundo & Sí & 6 & $1,2,3$ & Sí & $1,2,3,4$ \\
\hline La vanguardia & Sí & 14 & $1,2,3$ & Sí & $1,2,3,4,5$ \\
\hline Sur & Sí & 21 & $1,2,3$ & Sí & $1,2,3,4,5$ \\
\hline La voz de Galicia & Sí & 13 & $1,2,3$ & Sí & $1,2,3$ \\
\hline
\end{tabular}

(*) 1. Menús, 2. Noticias, 3. Llamada en portada - $\left(^{* *}\right)$ 1. Genérica, 2. Secciones, 3. Noticias, 4. Especiales, 5. Lectores

Tabla 2. Acceso y tipos (cómputos totales)

\begin{tabular}{|l|c|c|c|c|c|}
\hline \multicolumn{1}{|c|}{ Periódico } & $\begin{array}{c}\text { 6. Identidad de } \\
\text { estilo y diseño }\end{array}$ & $\begin{array}{c}\text { 7. Indicadores } \\
\text { de imagen }(*)\end{array}$ & $\begin{array}{c}\text { 8. Nitidez de las } \\
\text { miniaturas }\end{array}$ & $\begin{array}{c}\text { 9. Mezcla fotos } \\
\text { con vídeos }\end{array}$ & $\begin{array}{c}\text { 10. Mezcla fotos } \\
\text { con gráficos }\end{array}$ \\
\hline El mundo & No & $1,2,3,4$ & Sí & No & No \\
\hline La vanguardia & No & $1,2,3$ & Sí & No & No \\
\hline Sur & No & $1,2,4$ & Sí & No & No \\
\hline La voz de Galicia & No & $1,2,3$ & Sí & No & No \\
\hline
\end{tabular}

(*) 1. Miniaturas, 2. Números, 3. Iconos o botones, 4. Cursor

Tabla 3. Aspecto y configuración (cómputos totales)

\begin{tabular}{|l|c|c|c|c|}
\hline \multicolumn{1}{|c|}{ Periódico } & $\begin{array}{c}\text { 11. Idéntico } \\
\text { funcionamiento }\end{array}$ & $\begin{array}{c}\text { 12. Presentación } \\
\text { automática }\end{array}$ & 13. Control del lector & $\begin{array}{c}\text { 14. Ampliación } \\
\text { de tamaño }\end{array}$ \\
\hline El mundo & No & No & Sí & Sí \\
\hline La vanguardia & No & No & Sí & No \\
\hline Sur & No & No & Sí & No \\
\hline La voz de Galicia & No & Sí & Sí & No \\
\hline
\end{tabular}

Tabla 4. Funcionalidad (cómputos totales)

\begin{tabular}{|l|c|c|c|c|c|}
\hline \multicolumn{1}{|c|}{ Periódico } & $\begin{array}{c}\text { 15. Todas las fotos } \\
\text { con pies y textos }\end{array}$ & $\begin{array}{c}\text { 16. Textos } \\
\text { contextualizadores }\end{array}$ & $\begin{array}{c}\text { 17. Noticias con } \\
\text { galería propia }\end{array}$ & $\begin{array}{c}\text { 18. Fotos } \\
\text { multiuso }\end{array}$ & $\begin{array}{c}\text { 19. Vínculo desde } \\
\text { galería a noticias }\end{array}$ \\
\hline El mundo & Sí & $100 \%$ & Sí & $>50 \%$ & $>50 \%$ \\
\hline La vanguardia & Sí & $100 \%$ & Sí & $100 \%$ & $100 \%$ \\
\hline Sur & No & $<25 \%$ & No & $>50 \%$ & $<25 \%$ \\
\hline La voz de Galicia & Sí & $100 \%$ & Sí & $<25 \%$ & $0 \%$ \\
\hline
\end{tabular}

Tabla 5. Contextualización (cómputos totales)

de contenido, configuración y funcionalidad particulares. La ampliación para percibir mayor grado de detalle, con la consiguiente mejora en la calidad de las imágenes y un avance en la mejora de la contextualización son los principales retos a superar.

d) La presencia de pies de foto con textos explicativos como práctica mayoritaria, junto con la creciente inclusión de galerías en páginas interiores de noticias, pueden entenderse como indicativos de una toma de conciencia por parte de los editores en el sentido de avanzar hacia una mejor contextualización informativa de las fotografías.

e) El apoyo de pies textuales y títulos es insuficiente para la comprensión integral de las noticias a las que aluden las fotos. La fórmula más lograda para superar esta limitación es situar vínculos directos a la noticia desde la foto de la galería. De esta forma, sería posible entender las galerías como género informativo de naturaleza hipertextual, que dota al relato noticioso de una articulación peculiar sobre la base de la fotografía.

f) Los cuatro diarios analizados presentan bastantes similitudes en cuanto a diseño, acceso, funcionamiento y tipo de las galerías, y más divergencias en cuanto a contextualización informativa de las fotos, destacando en este sentido las ediciones digitales de La vanguardia y El mundo.

\section{Bibliografía citada}

Armentia-Vizuete, José-Ignacio. "Los diarios digitales siguen buscando su propia identidad tras una década de existencia". Estudios sobre el mensaje periodístico, 2005, n. 11, pp. 9-22.

http://revistas.ucm.es/inf/11341629/articulos/ESMP0505110009A.PDF 


\section{Le ayudamos a crear Bibliotecas Virtuales}

\section{desde la digitalización de materiales bibliográficos hasta la asignación de} metadatos y su implementación en la red, conforme a la normativa internacional.

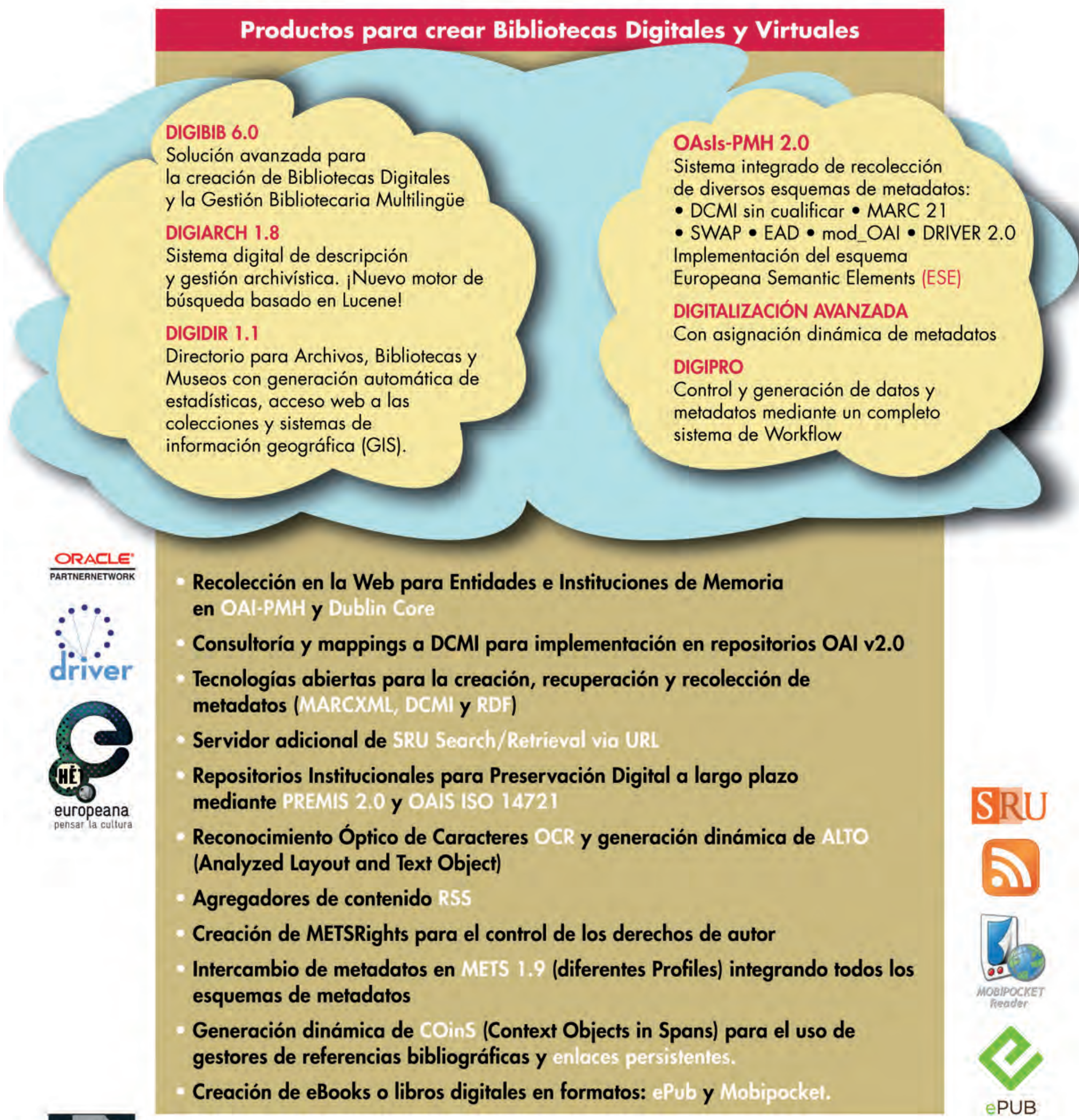

Validación en el Data Providers de la Open Archives Intiative. Genera un Sitemap para Google.

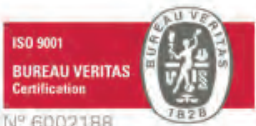

